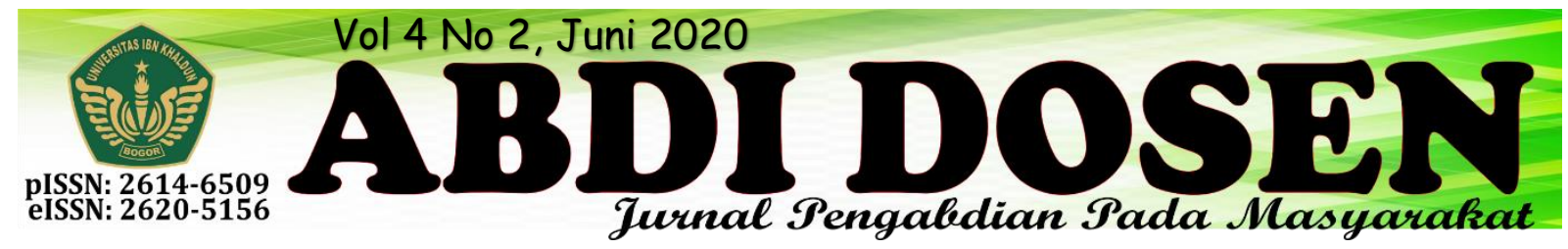

\title{
PEMBUATAN ALAT PENYULINGAN SAMPAH PLASTIK MENJADI BAHAN BAKAR MINYAK DI DESA SUKARAKSA
}

\author{
Mohammad Muhyidin Nurzaelani ${ }^{1}$, Rofiah $^{2}$ \\ m.muhyidin@uika-bogor.ac.id ${ }^{1}$ \\ rofiah@uika-bogor.ac.id ${ }^{2}$ \\ Fakultas Keguruan dan Ilmu Pendidikan Universitas Ibn Khaldun ${ }^{1}$, Fakultas Agama Islam Universitas Ibn \\ Khaldun $^{2}$
}

\begin{abstract}
ABSTRAK
Penggunaan plastic bagi kehidupan masyarakat masih angat tinggi, hal ini menyebabkan permasalahan sampah di dalam kehidupan sehari-hari. Permasalahan tersebut perlu dijadikan seorotan khusus, bagaimana menanggulangi sampah plastik tersebut. Di desa Sukaraksa Kec. Cigudeg Kab. Bogor tempat pelaksanaan KKN tematik kelompok 43 \& 44. Dilkakukan ushaa untuk menanggulangi permasalahan sampah dan untuk membantu meningkatkan taraf ekonomi masayrakat sekitar dengan cara pembuatan sistem pengoalahan plastic menjadi Bahan Bakar Minya (BBM). Dengan pengolahan tersebut potensi yang didapat adalah $1 \mathrm{Kg}$ sampah plasik dapat disuling menjadi +/- 1 liter BBM. Bahan bakar yang dihasilkan dapat digunakan sebagai bahan bakar kendaraan bermotor dan mesin air, serta keperluan lainya.
\end{abstract}

\section{Kata Kunci : Bahan Bakar, Penyulingan, Sampah Plastik}

\section{PENDAHULUAN}

Dewasa ini penggunaan plastik dalam kehidupan sehari-hari masyarakat sangat tinggi. Menurut Suhadi (2010) dalam Hiola dan Lalu (2017), "peningkatan populasi manusia menyebabkan permintaan pangan selalu bertambah. Disamping itu, kompleksnya kebutuhan dan peningkatan pola hidup masyarakat memacu perkembangan berbagai industri". Efek dari aktifitas tersebut berdampak pada kehidupan di masyarakat, yaitu penumpukan sampah yang sangat banyak, yang sebagian besar terdiri dari sampah plastik.

$$
\text { Penggunaan plastik sendiri }
$$

diakibatkan karena bertambah banyaknya populasi masyarakat dan juga industri yang berkembang di sekitar masyarakat. Hal ini dididukung juga dengan kelebihan- kelebihan yang dimiliki oleh bahan plastik itu sendiri jika dibandingkan dengan bahan lainya, banyak kelebihan yang dimiliki plastik yaitu, murah, ringan, dan cukup kuat. Dibalik banyaknya kelebihan tersebut plastik juga memeliki kekukrangan yaitu ketika pastik sudah tidak digunakan, atau sudah menjadi sampah makan bahan plastik akan sangat sulit terurai. Sedangkan kebutuhan penggunaaan plastik di Indonesia mengalami peningkatan rata-rata $200.000 \mathrm{~kg}$ per tahun. Saat ini sampah plastik seperti dikatakan oleh Rahyani (2001) dalam Hiloa dan Lalu (2017) yaitu "pada umumnya hanya dibuang (lanffill), dibakar atau didaur ulang (recycle). Proses tersebut belum menyelesaikan semua permasalahan limbah plastik, apabila dibakar pada suhu rendah, limbah plastik 
menghasilkan senyawa yang berbahaya yang bersifat karsinogen seperti poly chloro dibenzodioxins dan poly chloro dibenzofurans". Penguraian limbah plastik secara alami membutuhkan waktu yang lama karena sulitnya limbah plastik tersebut untuk diurai. Menurut Prihatmoyo dkk (2018), "limbah plastik membutuhkan waktu kurang lebih 100 tahun agar dapat terurai dengan sempurna".

Kondisi lingkungan masyararakat yang belum mengerti bagaimana penanganan sampah yang sangat banyak baik itu sampah organik maupun nonorganik, maka masyarakat hanya melakukan penanganan berupa pembuangan kemudian sampah dibakar begitu saja dan tidak memilah yang mana jenis sampah organik dan non-organik. Sedangkan sampah yang dibakar dan dibuang dapat menimbulkan polusi udara, pencemaran tanah, serta menjadi wabah penyakit. Oleh karena itu, program pengelolaan sampah plastik menjadi BBM di sampaikan kepada masyarakat dan program tersebut mendapat antusiasme cukup baik dari masyarakat sekitar. Selain itu, dapat memanfaatkan sampah plastik sebagai barang bermanfaat, program ini juga dapat memberikan peluang bisnis/ nilai jual bagi masyarakat.

\section{Perumusan Masalah}

\section{PEMBAHASAN}

\section{a. Program Pengelolaan Sampah Plastik menjadi Bahan Bakar Minyak (BBM)}

Pelaksanaan program pengelolaan sampah plastik menjadi BBM ini menjadi salah satu topik utama pada program Kuliah Kerja Nyata (KKN) yang dilakukan di Desa Sukaraksa Kp. Parakan Tiga Kecamatan Cigudeg Kabupaten Bogor.
Rumusan masalah pada penelitian ini yaitu bagaimana cara pembuatan alat penyulingan sampah plastik menjadi bahan bakar minyak untuk mengurangi permasalahan sampah plastik di Desa Sukaraksa?

\section{Tujuan Penelitian}

Tujuan kegiatan "Penyulingan Sampah Plastik menjadi Bahan Bakar Minyak" ini diharapkan menjadi solusi permasalahan sampah plastik di Desa Sukaraksa, serta mendorong masyarakat memiliki semangat dalam pengeleolaan sampah terutama sampah non-organik (sampah plastik) menjadi sampah memiliki nilai jual, sehingga selain mengurangi dampak pencemaran lingkungan, tetapi juga membantu perekonomian masyarakat sekitar seperti merubah sampah tersebut menjadi Bahan Bakar Minyak (BBM).

\section{Tujuan Penelitian}

Penyulingan sampah plastik ini menggunakan metode Pirolisis. Proses pirolisis sampah plastik merupakan proses dekomposisi senyawa organik yang terdapat dalam plastik melalui proses pemanasan dengan sedikit atau tanpa melibatkan oksigen. Pada proses pirolisis senyawa hidrokarbon rantai panjang yang terdapat pada plastik diharapkan dapat diubah menjadi senyawa hidrokarbon yang lebih pendek dan dapat dijadikan sebagai bahan bakar alternatif.

Program ini kami susun karena melihat latar belakang dari masyarakat yang cukup rendahnya tingkat kesejahteraan masyarakat dan kurang sadarnya masyarakat dalam menjaga kebersihan lingkungan sekitar seperti kebiasaan membuang sampah bukan pada tempatnya menjadi penyebab timbulnya beberapa masalah, diantaranya menimbulkan 
berbagai macam penyakit misalnya muntaber, disentri, tipus, dll. Oleh karena itu, program ini bekerjasama antara mahasiswa fakultas kesehatan masyarakat dengan menyampaikan informasi terkait pentingnya menjaga kebersihan lingkungan sekitar terutama kebersihan dari sampah non-organik (plastik). Karena sampah nonorganik terutama plastik termasuk ke dalam jenis sampah yang sulit terurai maka dari program ini mahasiswa bidang ekonomi juga memanfaatkan sampah/limbah plastik untuk kelola menjadi bahan yang berguna atau bernilai dapat meningkatkan perekonomian masyarakat kp. Parakan Tiga Desa Sukaraksa. Dengan membuat sebuah gagasan permberdayaan lingkungan dengan memanfaatkan sampah sampah menjadi suatu nilai yang memiliki harga. Bank sampah menjadi salah satu pilihan program kami karena selain bermanfaat bagi lingkungan sekitar, program ini pun dapat dimanfaatkan sebagai salah satu penghasilan masyarakat setempat. Dalam hal ini kami memanfaatkan sampahsampah plastik untuk diolah menjadi Bahan Bakar Minyak (BBM) melalui penyulingan dengan beberapa tahap ataupun langkah langkah yang harus dilalui. Untuk memulai program bank sampah awalnya diperlukan sebuah organisasi yang berguna dalam pengelolaan sampah sampah tersebut. Oleh karena itu sebelum mengembangkan alat, pemberian informasi kepada masyarakat sangat penting agar masyarakat dapat ikut andil dan berperan dalam program ini. Organisasi bank sampah ini memerlukan adanya keterlibatan masyarakat dan pemerintah desa diantaranya:

1. Ketua/direktur, adapun peran dan fungsinya yaitu: a. Melakukan pengawasan kegiatan masing-masing jabatan agar sesuai dengan prosedur kerja standar (SOP).

b. Membuat rencana kerja dan target yang harus dicapai masing-masing divisi.

c. Menjadi pemecah masalah terhadap masalah yang dihadapi oleh masingmasing divisi.

d. Melakukan evaluasi terkait kenerja masing-masing divisi terhadap targettarget yang ingin dicapai serta evaluasi terkait keuangan kegiatan.

e. Sebagai penanggungjawab keuangan kegiatan dari bank sampah.

f. Mengontrol pengupahan dan insetif pekerja bank sampah.

2. Administrasi/teller, peran dan fungsinya:

a. Pelayanan terhadap nasabah, dan tamu yang datang ke kantor bank sampah.

b. Menjalin komunikasi dengan nasabah dan pelanggan.

c. Melakukan penginputan data pembelian berasarkan proses penimbangan yang dilakukan petugas pengambilan pada divisi operasional ke sistem komputer.

d. Menjurnalkan setiap transakasi pembelian dan penjualan sampah.

e. Menjurnalkan nilai sampah dari penimbangan sampah, pada buku tabungan bagi yang ingin ditabung dan buku induk.

f. Mendokumenkan setiap nota penjulan ke buku induk dan membuat laporan harian.

g. Menampung setiap formulir perseorangan, ataupun kelompok yang ingin bergabung sebagai nasabah.

h. Melegalisir data di buku tabungan, nota penimbangan atau nota penjualan.

i. Membuat arsip surat keluar dan surat masuk. 
j. Pelaporan kepada direktur.

3. Bendahara, peran dan fungsinya:

a. Pelaporan harian dan bulanan terkait penerimaan dan pengeluaran keuangan bank sampah beserta bukti-bukti dan pengarsipannya.

b. Membuat resuame keuangan terkait keuntungan dan hasil kegiatan bank sampah

c. Memberikan upah kepada pekerja.

d. Melakukan pembayaran sampah atau peminjaman uang sesuai permintaan teller.

e. Mengatur keuangan untuk kegiatan operasional bank sampah yang sesuai kebutuhan dari setiap divisi.

f. Melaporkan penerimaan dan pengeluaran keuangan pada direktur.

4. Pemilah/pengepul, peran dan fungsinya:

a. Menyiapkan area untuk pengambilan, serta peralatan yang akan digunakan untuk pengambilan sampah (mobil angkutan, timbangan portable, terpal, tali, nota, alat tulis, dan lain-lain).

b. Mengkomunikasikan dengan nasabah yang akan dilakukan pengambilan sampahn, terkait waktu dan titik pertemuan.

c. Melakukan pengambilan sesuai jadwal yang telah disepakati.

d. Mengambil sampah nasabah sesuai jenis sampah yang telah ditetapkan.

e. Melakukan penimbangan sampah.

f. Memberikan nota dua rangkap.

Untuk realisasi dari program ini kami juga melibatkan mahasiswa teknik untuk simulasi penyulingan sampah plastik menjadi bahan bakar minyak tersebut kepada masyarakat dengan membuat equipment pengolahan sampah plastik menjadi BBM. Alat yang dikembangkan merupakan sebuah mesin yang memilki fungsi sebagai pengolah limbah atau sampah plastik menjadi bahan bakar minyak. Equipment pengolahan sampah plastik menjadi BBM, juga sering disebut mesin "Pirolisis Plastik". "Pilorisis adalah teknik pembakaran sampah (limah plastik) tanpa $\mathrm{O}_{2}$ dan dilakukan pada suhu tinggi antara $800{ }^{\circ} \mathrm{C}$ sampai $1000{ }^{\circ} \mathrm{C}$ " (Ermawati, 2011). Kegunaan equipment pengolahan sampah plastik menjadi BBM untuk masyarakat, terkait permasalahan sampah yaitu mendapatkan sumber energi alternatif dalam mengolah sampah dan menambah perekonomian masyarakat. Alat dan bahan yang dibutuhkan untuk membuat mesin tersebut yaitu:

1. Tong

2. Selang besi

3. Botol/kaleng bekas

4. Lem besi atau las

\section{b. Cara kerja Mesin pengolah sampah pelastik menjadi BBM}

Seperti yang diketahui, jika plastik merupakan bahan terbuat dari minyak bumi. Sehingga proses perubahanya hanya dengan menggembalikan menjadi senyawa penyusunnya (senyawa asal). Proses pengolahan sampah plastik menjadi BBM menggunakan metode pirolisis, yaitu melakukan pemanasan sampah plastik tanpa oksigen pada suhu tertentu. Proses kerja mesin pengolah sampah menjadi BBM diantaranya:

1. Siapkan sampah plastik kering

2. Masukan sampah plastik ke dalam tong

3. Letakkan tong di atas tungku

4. Lalu, nyalakan api dengan kayu bakar

5. Bakar sampah plastik yang ada di dalam tong

6. Sampah plastik akan mengalami fase perubahan bentuk dan akan menjadi gas. 
7. Gas akan melalui sistem pendinginan dan terjadi kondensasi, kemudian hasil kondensasi dilakukan penyulingan berulang, dan membentuk cairan yang bersih. dan cairan inilah yang merupakan bahan bakar, yaitu minyak plastik. Cairan ini setara solar dan premium. BBM tersebut dapat digunakan di antaranya sebagai bahan bakar kendaraan bermotor dan mesin air. Hasil tersebut dapat meningkatkan perekonomian masyarakat.

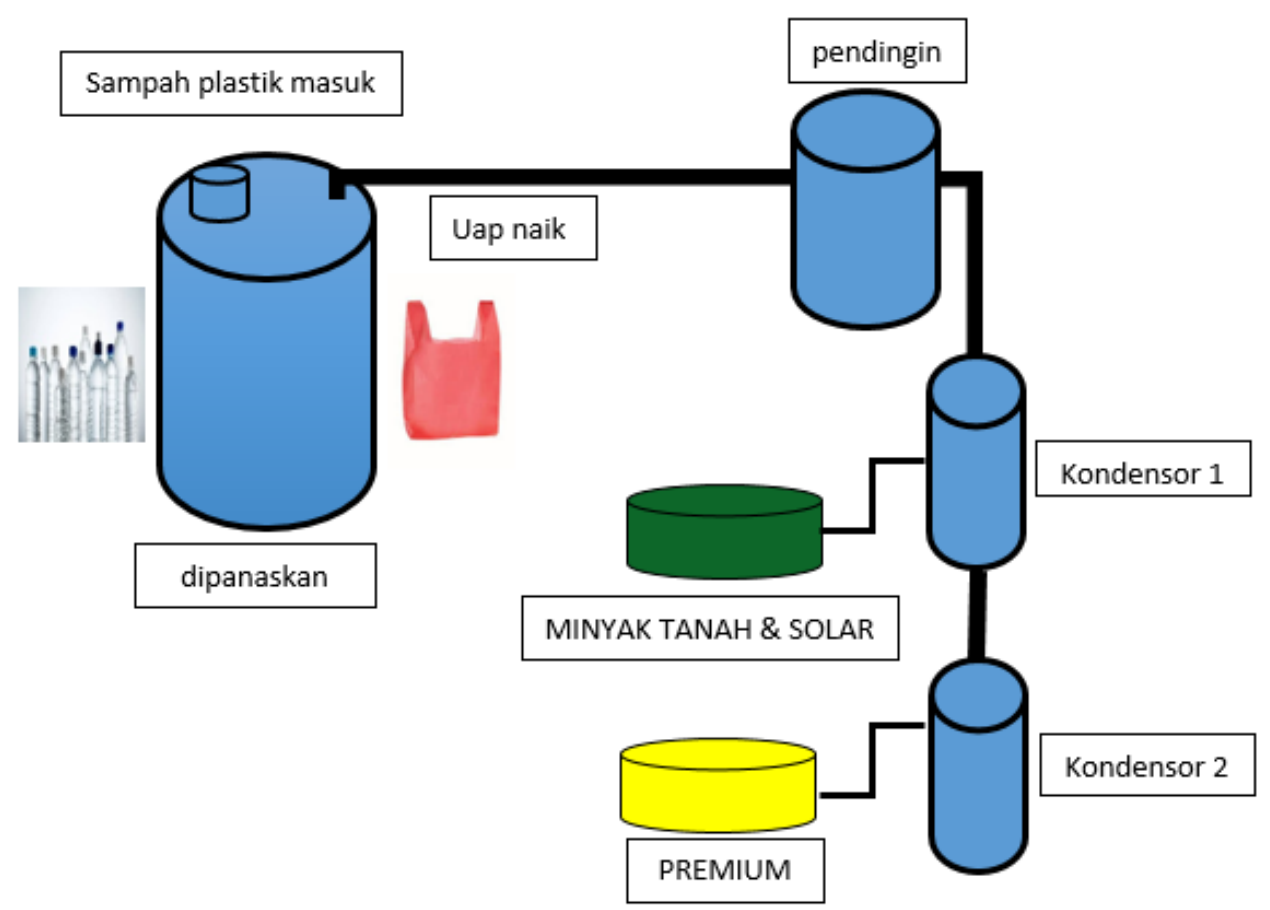

Gambar 1. Proses Penyulingan Sampah Plastik Menjadi Bahan Bakar Minyak

Pada Gambar 1, dapat dijelaskan bahwa sampah plastik $1 \mathrm{~kg}$ yang masuk ke dalam tabung reaksi kemudian dipanaskan sampai sampah plastik tersebut menguap. Lalu, uap hasil dari proses tersebut mengalir ke kondensor 1. Uap dalam kondesor 1 akan mengalami proses penyulingan menjadi minyak tanah dan solar. Sementara itu, uap yang tidak tersuling dikondensor 1 akan mengalir ke kondesor 2. Uap di dalam kondensor 2 mengalami penyulingan dan menghasilkan cairan bahan bakar minyak yang setara dengan premium. Dari percobaan penyulingan $1 \mathrm{~kg}$ sampah plastik dapat menghasilkan kurang lebih 1 liter BBM. Semua jenis plastik dapat digunakan dalam penyulingan bahan bakar minyak. Akan tetapi dari hasil percobaan sampah bahan plastik yang menghasilkan BBM dengan kualitas bagus adalah sampah plastik dari bahan bekas botol minum dan kantong plastik. Kualitas BBM yang dihasilkan dari penyulingan sampah plastik tersebut sama dengan bahan bakar minyak jenis premium. 


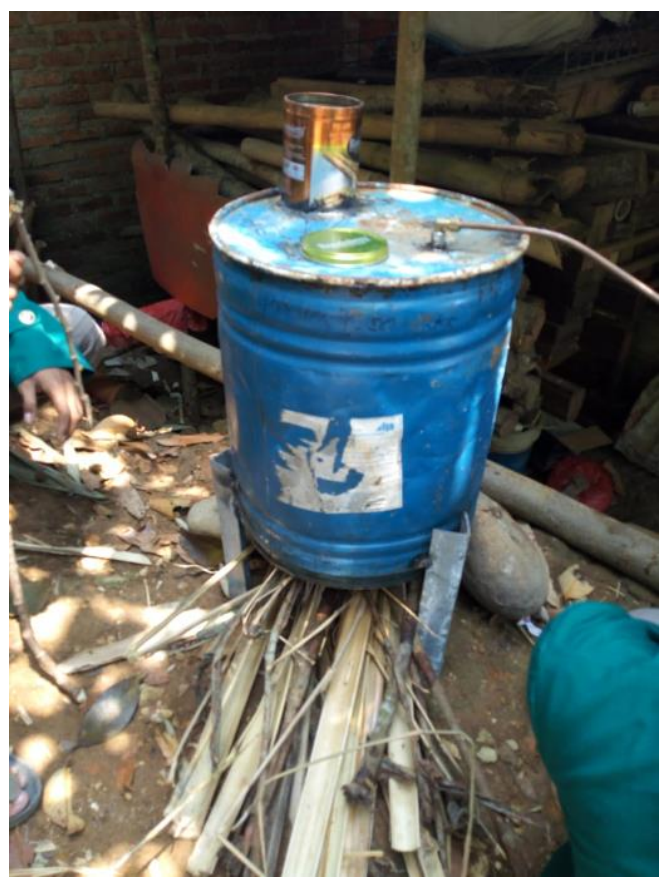

Gambar 2. Alat Penyulingan Sampah Plastik Menjadi Bahan Bakar Minyak

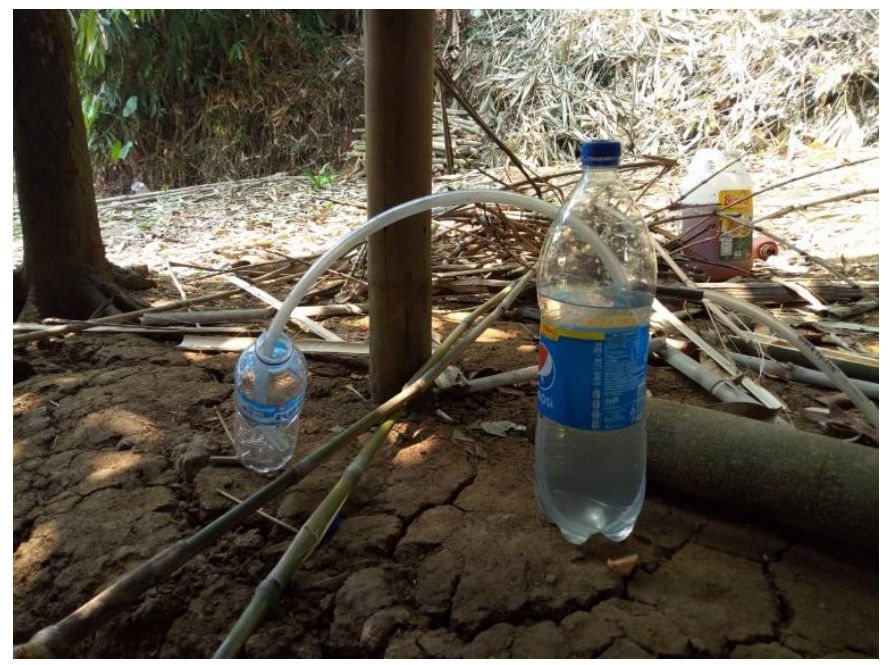

Gambar 3. Botol Pendingin dan Botol Penampung BBM

\section{KESIMPULAN}

Berdasarkan dari hasil kegiatan, pengamatan, maupun pelaksanaan program kerja KKN terkait Penyulingan Sampah Plastik menjadi Bahan Bakar Minyak. Maka kelompok 43 dan 44 KKN UNIVERSITAS IBN KHALDUN BOGOR 2019 di Kp. Parakan Tiga Desa Sukaraksa Kecamatan Cigudeg Kabupaten Bogor mengambil beberapa kesimpulan yaitu:
1. Alat penyulingan sampah plastik menjadi bahan bakar minyak (BBM) dapat digunakan sebagai salah satu solusi permasalahan sampah plastik di Desa Sukaraksa.

2. Program ini cukup membantu masyarakat, terkait peningkatan informasi, ilmu pengetahuan dan penanganan pengelolaan mengenai sampah yang efektif dan kondusif. Program ini ditunjang dengan 
antusiasme dari masyarakat, sehingga setiap kegiatan berjalan dengan sangat baik.

3. Kegiatan ini sebagai salah satu cara mengelola sampah yang cukup efisien dalam penanganan masalah sampah yang ada di masyarakat kp. Parakan Tiga Desa Sukaraksa Kecamatan Cigudeg Kabupaten Bogor terutama jenis sampah plastik yang diolah menjadi Bahan Bakar Minyak yang dapat mengurangi

\section{DAFTAR PUSTAKA}

Ermawati, R. 2011. Konversi Limbah Plastik Sebagai Sumber Energi Alternatif. Jurnal Riset Industri Vol. V, No. 3. Jakarta : Balai Besar Kimia dan Kemasan, Kementerian Perindustrian.

Hiloa, R., dan Lalu, N. 2017. Pengolahan Sampah Plastik dengan Metode Penyulingan Sederhana Menjadi Minyak Mentah di Desa Dambalo Kecamatan Tomilito Kabupaten Gorontalo Utara. Laporan Akhir KKS Pengabdian. Gorontalo : LPPM Universitas Negeri Gorontalo.

Mujiarto, I., 2005. Sifat dan Karakteristik Material Plastik dan Bahan Aditif. Jurnal Traksi Vol.3, No.2, AMNI Semarang.

I. Sundarta, A. Sari and H. P. Wibowo, "Pengelolaan Limbah Organik Menjadi Kompos melalui Pembuatan pencemaran lingkungan dan meningkatkan perekonomian masyarakat.

4. Keberhasilan program KKN berkaitan erat dengan kerja sama yang dilakukan antara mahasiswa, pemerintah desa, masyarakat sekitar, serta semua pihak yang terkait dengan pelaksanan kegiatan $\mathrm{KKN}$, tanpa didasari kerja sama yang kuat, program kerja KKN kami tidak akan berjalan seperti yang diharapkan.

Tong Super" Jurnal Pengabdian Pada Masyarakat, 2018.

Prihatmoyo, E., Dermawan, D., dan Bisono, F. Rancang Bangun Mesin Destilator Pengubah Limbah Plastik Menjadi Minyak. Proceedings Conference on Design and Manufacture and Its Aplication. Vol. 2, No. 1. Surabaya : Politeknik Perkapalan Negeri Surabaya.

Rodiansono. 2011. Aktivitas Katalis $\mathrm{NiMo/Zeolit} \mathrm{dan} \mathrm{NiMo/Zeolit-Nb2O5}$ untuk Reaksi Hidrorengkah Sampah plastik Polipropilena Menjadi Fraksi Bensin, Thesis Ilmu Kimia Universitas Gadjah Mada, Yogyakarta.

Suprihatin, A., dan Prihanto, D. 1996. Pengelolaan Sampah. Malang: PPPGT /VEDC Malang. 